\title{
Vegetation Phenology and Its Response to Climate Change in Extremely Arid Area: A Case Study of Populus Euphratica in The Upper Tarim River Basin, NW China
}

\section{Hualin Li}

College of Soil and Water Conservation, Beijing Forestry University

Jianzhong Feng

Agricultural Information Institute, Chinese Academy of Agricultural Sciences

Linyan bai ( $\sim$ baily@aircas.ac.cn )

Key Laboratory of Digital Earth Sciences, Aerospace Information Research Institute, Chinese Academy of Sciences https://orcid.org/0000-0002-9376-3255

Jianjun Zhang

College of Soil and Water Conservation, Beijing Forestry University

\section{Research}

Keywords: Tarim River, Populus euphratica, phenology, leaf area index (LAl), dynamic threshold method, canonical correlation analysis (CCA)

Posted Date: May 13th, 2021

DOI: https://doi.org/10.21203/rs.3.rs-513074/v1

License: (c) (i) This work is licensed under a Creative Commons Attribution 4.0 International License.

Read Full License 


\section{Abstract}

Quantifying the phenological variations of Populus euphratica (P. euphratica) resulting from climate change is vital for desert ecosystems in extremely arid regions. $P$. euphratica phenology and its response to climate change are lacking in extremely arid area. In this study, a modified method was proposed to explore $P$. euphratica phenology and its response to climate change using 15-year Global LAnd Surface Satellite (GLASS) leaf area index (LAI) time-series data (2002-2016) in the upper Tarim River basin. The start of the growing season (SOS), length of the growing season (LOS), and end of the growing season (EOS) were obtained with the dynamic threshold method from the reconstructed growth time series curve by using the Savitzky-Golay filtering method. The grey relational analysis (GRA) method was utilized to analyze the correlation between the phenological features of $P$. euphratica and climatic factors. Importantly, we also revealed the positive and negative effects between interannual climate factors and $P$. euphratica phenology using the canonical correlation analysis (CCA) method, and the interaction between the SOS in spring and EOS in autumn. The results revealed that the SOS of $P$. euphratica was delayed by about 5.3 days/10a, while EOS was advanced by about 3.1 days/10a. The phenology of $P$. euphratica was extensively changed, with high spatial heterogeneity. Spring sunshine duration (SD) and average air temperature (AT) controlled the SOS and EOS, although the impacts of average relative humidity (RH) and precipitation (PR) on phenology cannot be overlooked. The SOS was positively correlated with the EOS, implying a later SOS may generally be accompanied by a later EOS. Global warming may lead to SOS advance and EOS delay, and the increase of SD may lead to later SOS and earlier EOS. Groundwater was found to be a key factor for controlling $P$. euphratica phenology than runoff in this region.

\section{Introduction}

Vegetation phenology is the research of events in the plant life cycle, and how these events adapt to climate changes (Zhang et al., 2018a; Nilsson et al., 2019), which makes it the most intuitive and sensitive biological indicator of climate change. Climate change such as modified precipitation, increasing temperature, and increasing frequency of extreme weather events will change the vegetation phenology (He et al., 2020), which have extensive effects on plant community structure, plant distribution, energy cycle, vegetation ecosystem, and primary production of vegetation (Gonsamo et al., 2013; Schwieder et al., 2016; Meng et al., 2019; Pabon-Moreno et al., 2020; Shen et al., 2020). Altered phenological timing, furthermore, may have negative effects on species interactions in the food chain such as migration, survival, reproduction, and occupying feeding habits (Burgess et al., 2018; Misra et al., 2021). Therefore, a better understanding of how vegetation phenology to climate change can improve the accuracy of phenological simulation models and provide a scientific reference for future management of vegetation ecosystems.

The plant growth such as leaf unfolding, flowering, fruiting, and leaf senescence is recorded to reflect the phenological characteristics of vegetation based on ground monitoring sites of phenology. However, this method has some limitations in spatiotemporal scale and biome-scale (Zhang et al., 2021a). Therefore, the remote sensing technique for phenological monitoring, which is used to simulate various logistics 
regression models through long-term series remote sensing data and to extract vegetation phenology (i.e., the start of the growing season (SOS), length of the growing season (LOS), and end of the growing season (EOS)) from suitable models, has been widely applied to explore the spatial-temporal variations of vegetation phenology at the regional and global scales (Steven P. Norman 2017; Araghi et al., 2019; Tong et al., 2019; Bornez et al., 2020; Geng et al., 2020; Xu et al., 2020). However, there is a wide range of mixed pixels in satellite remote sensing data, the spatial resolution of remote sensing data will affect the accuracy of vegetation phenological feature inversion, especially in the extreme arid areas where the vegetation distribution is more sparse and the coverage is lower. In addition, previous researches on vegetation phenology have focused on the plant phenology change trends (Delbart et al., 2015; Suepa et al., 2016; Lim et al., 2020), phenology changes of different vegetation types (Yuan et al., 2020), temperature (Ma et al., 2020; Zou et al., 2020; Xu et al., 2021), rainfall (Meier et al., 2015; Huang et al., 2020; Li et al., 2020), aspect (An et al., 2018), altitude (Zou et al., 2020), solar radiation (Jin et al., 2017), and other single climatic factors affecting vegetation phenology. Therefore, there is still a need to demonstrate the relationship of the preseason, interannual, and multi-climatic factors with phenology, and whether what kind of interaction exists between the SOS and EOS requires further study.

Arid and semi-arid ecosystems are important parts of the Earth's climate system, covering $41 \%$ of the Earth's land surface (Schimel, 2010; Yuan et al., 2014; Yu et al., 2021). These regions are characterized by harsh environments and little rainfall, especially in highly arid areas, where the average annual rainfall is often $<60-100 \mathrm{~mm}$ (Noy-Meir, 1973). The Tarim River Basin is located in the hinterland of Eurasia, an extremely arid area. This region is highly vulnerable and sensitive to climate change due to the particular features of comprising mountains and a mosaic of inner-mountain basins (Zhou et al., 2020). Populus euphratica ( $P$. euphratica), an ancient, precious, endangered species, is a constructive tree in extremely arid areas (Zhou et al., 2020). P. euphratica is a vital part of the extreme drought ecosystem in this region due to its advantageous characteristics such as cold resistance, heat resistance, drought resistance, wind-sand resistance, and salt-alkali resistance (Li et al., 2019a). In the upper Tarim River basin, since there are less affected by implementing the Ecological Water Conveyance Project than the lower Tarim River, the results that the response of $P$. euphratica phenology to climate change is more believable. However, research in this field mainly focuses on the relationship between vegetation and groundwater (Gou and Miller, 2014; Zhou et al., 2020), changes in rainfall and temperature under climate change and global warming, and its impact on water resources (Xu et al., 2010; Chen et al., 2015; Lang et al., 2016; Keram et al., 2019; Wu et al., 2020), and the impact of water on physical and chemical indicators of vegetation growth (Zhou et al., 2010; Eusemann et al., 2013; Yuan et al., 2014; Yu et al., 2021). To date, few if any studies have revealed the dynamics of $P$. euphratica phenology and its response to climate change in arid areas.

The novelty of this study is that a modified method was proposed to explore $P$. euphratica phenology and its response to climate change using 15-year Global LAnd Surface Satellite (GLASS) leaf area index (LAI) time-series data (2002-2016) in the upper Tarim River basin. A gridded spatial sampling strategy, which can reduce the accuracy error caused by many mixed pixels in satellite remote sensing data, was used to extract the LAI information of $P$. euphratica from the GLASS LAl time-series data, and the phenological 
information (i.e., SOS, LOS, EOS) was obtained with the dynamic threshold method from the reconstructed growth time series curve by using the Savitzky-Golay filtering method. The grey relational analysis (GRA) and canonical correlation analysis (CCA) methods were utilized to explore the relationship between phenology and multi-climatic factors. Specifically, The main objectives of this study were to $\mathbb{Z}$ quantitatively reveal the spatio-temporal characteristics and change trends of $P$. euphratica phenology, $\nabla$ identify the key meteorological factors and key periods that affect the phenology of $P$. euphratica, and $\nabla$ confirm whether the beginning and the end of the $P$. euphratica growing season influence each other. The results provide insights into quantitative assessment of spatio-temporal variations of $P$. euphratica phenology under climate change and provide a scientific reference for future management of the desert ecosystem.

\section{Materials And Methods \\ 2.1. Study area}

Through field investigation, P. euphratica was found to be mainly distributed along the upper reaches of the Tarim River and the Yerqiang River. Therefore, this investigation mainly focused on the upper Tarim River and the Yeerqiang River Basin, which was divided into three regions (Fig. 1b): Bachu (BC), Alaer (ALE), and Shaya (SY). The study area experiences a typical temperate arid continental climate, with long sunshine duration, strong annual evaporation, and low annual rainfall. The extreme minimum temperature is $-25^{\circ} \mathrm{C}$, the extreme maximum temperature is $39.4^{\circ} \mathrm{C}$, and the annual average temperature is $10.4^{\circ} \mathrm{C}$ (Zhou et al., 2020). The annual average precipitation is $30-50 \mathrm{~mm}$, and the annual potential evaporation is 2000-2900 $\mathrm{mm}$ (Zhou et al., 2010).

\subsection{Datasets}

The Global LAnd Surface Satellite (GLASS) leaf area index (LAI) has a temporal resolution of eight days and spans the period from 1981-2016. The LAl product from 1982-1999 was developed from AVHRR reflectance with a spatial resolution of $0.05^{\circ}$, and that from 2000-2017 with spatial resolutions of $1 \mathrm{~km}$ was derived from MODIS reflectance (Hu et al., 2021). The GLASS LAl data product is a national key project, and its dataset is superior to other similar products in terms of spatial and temporal accuracy (Li and Xiao, 2020). This product feature has significant advantages in the continuity of its time series and the integrity of its spatial scope (Xiang et al., 2014). Moreover, the GLASS LAI dataset has passed the verification analysis of the measurement data of the common international site, with the results demonstrating that the verification accuracy is higher than other similar products (Zhao et al., 2016b; Wang et al., 2017). Since $P$. euphratica has a small distribution area and low vegetation coverage, this study used the GLASS 1-km resolution data, which were from the National Earth System Science Data Sharing Infrastructure, National Science \& Technology Infrastructure of China (http://www.geodata.cn). A total of eight years of data from 2000-2016 were obtained, and all the LAl values were the original values of the GLASS LAl dataset, which were equal to 10 times the actual valued. 
This study used climatic data, including sunshine duration (SD), average air temperature (AT), average land surface temperature (ST), effective accumulated temperature (EA), average relative humidity (RH), and precipitation (PR). These data were derived from http://data.cma.cn/ from 2000-2016. Monthly and annual runoff data were derived from the Statistical Bulletin of the Ministry of Water Resources of the People's Republic of China (http://www.mwr.gov.cn/sj/\#tjgb). Additionally, in this study, based on Landsat TM/OLI long time series remote sensing data with 30-m resolution from 1990-2015, the distribution data of $P$. euphratica for 1990, 1995, 2000, 2005, 2010, and 2015 were extracted using the object-oriented classification method. These data were then used to select typical sample sites of $P$. euphratica.

\subsection{Methods}

The technique flowchart of this study is shown in Fig. 2, the research steps were as follows. $\otimes P$. euphratica samples were selected and extracted from LAl time series data using the gridded spatial sampling method. The growth time series curve of $P$. euphratica was then reconstructed using the Savitzky-Golay filtering method. $\otimes$ The phenological features of $P$. euphratica, including the SOS, EOS, and LOS, were extracted using the dynamic threshold method. $\otimes$ The Spatiotemporal characteristics of $P$. euphratica phenology were visualized using the kriging spatial interpolation method and trend analytical method. $\otimes$ The grey relational analysis (GRA) method was used to analyze the correlations between climatic factors and the SOS in three periods (spring, SOS preseason, annual), and the EOS in three

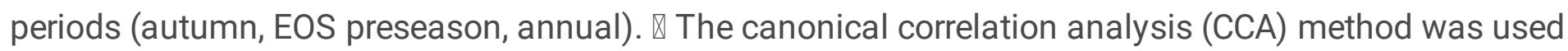
to explore the relationship between phenology (SOS, EOS) and interannual climatic factors (SD, AT, ST, EA, $\mathrm{RH}, \mathrm{PR})$.

\subsubsection{Extract LAl features}

Based on the distribution data of $P$. euphratica in 1990, 1995, 2005, 2010, and 2015, the regional composition sample data of $P$. euphratica, which fully met the $1 \mathrm{~km}^{2}$ area criterion were automatically identified by $1 \mathrm{~km} \times 1 \mathrm{~km}$ square window. Based on a gridded spatial sampling strategy, the LAl information was extracted from each sample in 2002, 2004, 2006, 2008, 2010, 2012, 2014, and 2016 using the GLASS LAI products.

\subsubsection{Filtering and reconstruction of LAl curves}

Although the GLASS LAl products have been processed to remove noise, the time series information of the extracted sample points still exhibits the "pseudo" peak phenomenon. Thus, the Savitzky-Golay (S-G) filtering method was utilized to remove the noise and reconstruct the LAl curves of $P$. euphratica. S-G filtering can be used to the time-series index data of different time scales and is not limited by sensor differences, so the noise in the original data can be removed using the minimum root mean square error (Cai et al., 2017). 
$Y_{j}^{\prime}=\frac{\sum_{i=-m}^{i=m} C_{i} Y_{j+1}}{N}$

Where $Y_{j}^{\prime}$ is the resultant LAI value, $Y_{j}$ is the original LAI value, $C_{i}$ is the coefficient for the LAI value of the filter, and $N$ is the number of convoluting integers and is equal to the smoothing window size $(2 m+1)$.

\subsubsection{Dynamic threshold method}

The dynamic threshold method is widely utilized to extract phenological features of vegetation because it has better spatiotemporal applicability (Hu et al., 2018; Guo et al., 2019). When the dynamic threshold method was proposed to extract phenological features, Jönsson and Eklundh (2002) suggested that the threshold at the SOS and EOS is 0.2 , which has been subsequently was used by many scholars in phenological research. This study combined remote sensing data with 2016 ground-based monitoring data and took into account existing research results. The SOS and EOS dates were obtained using various dynamic thresholds ranging from $0.1-0.4$ at 0.02 intervals. Then the results were verified to use ground-based monitoring data. Based on these tests, we opted to use thresholds of 0.2 and 0.3 to extract the SOS and EOS, respectively. We then used the following procedure, as illustrated by the flow chart in Fig. 3.

\subsubsection{Grey relational analysis (GRA)}

The relationship between many factors falls within a gray area, due to the limitations of people's understanding and the complexity of geographical phenomena, and it is difficult to objectively measure the degree of relevance by the relative correlation coefficient method (Li et al., 2019b). The grey relational analysis method makes up for the above shortcomings. GRA is not limited by sample type and probability distribution, so it is a new method to study investigate uncertain problems under limited information and data (He et al., 2018; Gao et al., 2020). Details of the principles and computation steps of the PNPI were presented in Li et al. (2019b).

\subsubsection{Canonical correlation analysis (CCA)}

Canonical correlation is a statistical analysis method used to study the correlation between two groups of variables and was first proposed by Hotelling in 1935 (Hotelling, 1935). It is also a dimensionality reduction technology, which is widely used in various fields (Ivanova et al., 2019). Vegetation phenology is not only related to climatic factors, but also the physiological characteristics of vegetation. The change of climatic factors may not lead to one-way phenological changes due to the interaction effects between the SOS in spring and the EOS in autumn (Wu et al., 2016; Shen et al., 2020). It is not rigorous to use simple climatic data to describe these changes. Therefore, the CCA method has been utilized to explore the relationship between phenological features and climatic factors, thereby inferring the interaction between the SOS and EOS. The principle and computation steps are detailed in Hotelling (1935).

\section{Results}




\subsection{Spatio-temporal variations of $P$. euphratica phenology 3.1.1. Analysis of SOS}

Interannual changes and trends of $P$. euphratica phenology (SOS, EOS) are shown in Fig. 4 in the upper Tarim River basin from 2002-2016. The SOS of $P$. euphratica was delayed about 5.3 days $/ 10$ a of this study area (Fig. 4d). The slope value was positive, indicating that the SOS showed a trend of postponement with time (Fig. 4e). The SOS in the Bachu (BC) region was delayed by 4.1 days $/ 10 \mathrm{a}$ (Fig. 4a), by 5.9 days/10a in the Shaya (SY) region (Fig. 4b), and by 5.9 days/10a in the Alaer (ALE) region (Fig. 4c). The variation range of the SOS in the ALE region was relatively small, while those in the $\mathrm{BC}$ and SY regions were larger (Fig. 4e).

Figure 5 presents the SOS spatial distribution of $P$. euphratica in the upper Tarim River basin from 20022016. The SOS dates of $P$. euphratica were earlier in the Bachu and Shaya regions, but later in the Alaer region (Fig. 5a). The SOS of $P$. euphratica varied from year to year in the same region and was the earliest in 2004. For the same year in the same region, the SOS dates of $P$. euphratica in different locations were quite different. In the BC and SY regions, the SOS of $P$. euphratica exhibited a spatial pattern of early in the west and late in the east (Fig. 5c, d), although there was little difference between the east and west SOS dates in the ALE region (Fig. 5b).

\subsubsection{Analysis of EOS}

In the study time series, the EOS of $P$. euphratica showed an advancement trend of about 3.1 days/10a (Fig. 4d). The interannual variation trend of $P$. euphratica in the SY and ALE regions had a slope $<0$, indicating an advancement trend (Fig. 4f), with the EOS advancing at the rate of 5.4 days/10a (Fig. 4b) and 4.6 days $/ 10$ a (Fig. 4c), respectively. In the BC region, however, the interannual variation trend of the EOS had a slope $>0$, indicating a delayed trend (Fig. 4 f), at the rate of 0.6 days $/ 10$ a (Fig. 4a).

The EOS spatial distribution of $P$. euphratica in the upper Tarim River basin from 2002-2016 is shown in Fig. 6. The end of the $P$. euphratica growing season in the BC and SY regions became late, while that in the ALE region became earlier (Fig. 6a). The EOS of $P$. euphratica varied among different years in the same region, and the EOS was the earliest in 2004 (Fig. 6b-d). In the same region, the spatial heterogeneity of the P. euphratica EOS in the same year was higher and the difference was greater. In the ALE and SY regions, the EOS of $P$. euphratica exhibited a spatial pattern of early in the west and late in the east (Fig. 6a, b), although there was little difference between the east and west EOS dates in the BC region (Fig. 6c).

\subsubsection{Analysis of LOS}

In the study time series, the LOS of the $P$. euphratica in the study area displayed a shortening trend, with the LOS shortening 9.2 days/10a (Fig. 7). and the LOS of $P$. euphratica in the BC, SY, and ALE regions shortening 3.3 days/10a, 12.7 days/10a, and 11.7 days/10a, respectively. The growing season length of $P$. euphratica differed among the different regions (BC, SY, ALE), with the rank order based on $P$. 
euphratica LOS being SY > BC > ALE. The spatial pattern distributions of interannual growth season length of different typical sample sites in the BC and SY regions were different, and the interannual fluctuation range was large. The $P$. euphratica LOS was relatively stable in the ALE region, however. The change trends of the $P$. euphratica LOS in the study area were similar, and the interannual change trends were the same in the BC, SY, and ALE regions.

\subsection{P. euphratica phenology response to climate change 3.2.1. Effects of key periods and climatic factors on phenology}

The GRA between phenology (SOS and EOS) and climatic factors (SD, AT, ST, EA, RH, PR) are presented in Fig. 8. The SOS of $P$. euphratica was mainly affected by spring climatic factors, while the EOS of $P$. euphratica was mainly affected by autumn meteorological factors. The SOS of $P$. euphratica was mainly affected by the climatic factors (0.65) in spring (March-May) (Fig. 8a), and less affected by the annual (January-December) climatic factors (0.48) or the SOS preseason (December-May) of climatic factors (0.50) (Fig. 8c, 8e). Moreover, the influence of spring climatic factors in the different regions (BC, ALE, SY) on the SOS of $P$. euphratica was greater than that of the annual climatic factors or the SOS preseason climatic factors. The EOS of $P$. euphratica was mainly affected by the meteorological factors $(0.69)$ in autumn (September-November) (Fig. 8b), and less affected by the annual (January-December) meteorological factors (0.52) or the EOS preseason (December-May) meteorological factors (0.67) (Fig. 8d, 8f). Moreover, the influence of autumn meteorological factors on the EOS of $P$. euphratica was greater than that of the annual meteorological factors or the EOS preseason meteorological factors in the $B C$ and $A L E$ regions.

Different meteorological factors had different effects on phenology (Fig. 8). On the whole, the sunshine duration (SD) and average air temperature (AT) had the greatest correlation with $P$. euphratica phenology (SOS, EOS), followed by the average relative humidity (RH), effective accumulated temperature (EA), and average land surface temperature (ST). Precipitation (PR), however, exerted the least effect on $P$. euphratica phenology. The effects of sunshine duration (0.75), average air temperature (0.76), effective accumulated temperature (0.72), and average relative humidity (0.72) on the SOS of $P$. euphratica were greater than those of average land surface temperature (0.66) and precipitation (0.30). The effects of sunshine duration (0.86), average air temperature (0.80), effective accumulated temperature (0.75), and average relative humidity (0.74) on the EOS of $P$. euphratica were greater than those of average land surface temperature (0.68) and precipitation (0.33).

\subsubsection{Influence of interannual climatic change on phenology}

Figure 9 shows the CCA patterns between phenology (SOS and EOS) and climatic factors (SD, AT, ST, EA, $\mathrm{RH}, \mathrm{PR})$. A total of two pairs of canonical variables were extracted, the first of which $\left(\mathrm{U}_{1}, \mathrm{~V}_{1}\right)$ was statistically significant $(P<0.05)$. The results showed that the first pair of canonical correlation variables 
revealed a clear correlation between phenology and climatic factors, as indicated by the canonical correlation coefficient of 0.83 . The canonical variable $U_{1}$ had a significant positive correlation with SOS but a significant negative correlation with EOS, with typical load coefficients of 0.77 and -0.98 , respectively. The typical variable $\mathrm{V}_{1}$ had positive correlations with average land surface temperature, average air temperature, and effective accumulated temperature, with the typical load coefficients of 0.71 , 0.66 , and 0.55 , respectively. $V_{1}$ had negative correlations with precipitation, sunshine duration, and average relative humidity, however, with typical load coefficients of $-0.16,-0.53,-0.30$, respectively. These results generally indicated that the SOS had negative correlations with average land surface temperature and average air temperature, and a positive correlation with sunshine duration. The EOS had positive correlations with average land surface temperature and average air temperature, and negative correlations with sunshine duration and average relative humidity.

The canonical redundancy analysis (Table 1 ) revealed that the first pair of canonical variables $\mathrm{U}_{1}$ could explain $77.62 \%$ of the intra-group variation and $18.69 \%$ of the other group variation. The typical variable $V_{1}$, however, could explain $27.37 \%$ of the intra-group variation and $53.01 \%$ of the other group variation. Therefore, we could infer that the SOS and EOS of $P$. euphratica affect each other. The phenology (SOS, EOS) of $P$. euphratica is not only related to meteorological factors but also the physiological characteristics of $P$. euphratica.

Table 1

Canonical redundancy analyses between $\mathrm{U}_{1}$ and $\mathrm{V}_{1}$

\begin{tabular}{|lllll|}
\hline & $\begin{array}{l}\mathrm{X}_{1} \text { canonical } \\
\text { variable }\end{array}$ & $\begin{array}{l}\mathrm{X}_{2} \text { canonical } \\
\text { variable }\end{array}$ & $\begin{array}{l}\mathrm{Y}_{1} \text { canonical } \\
\text { variable }\end{array}$ & $\begin{array}{l}\mathrm{Y}_{2} \text { canonical } \\
\text { variable }\end{array}$ \\
\hline $\begin{array}{l}\mathrm{U}_{1} \\
(\%)\end{array}$ & 77.62 & 22.38 & 18.69 & 6.97 \\
\hline $\begin{array}{l}\mathrm{V}_{1} \\
(\%)\end{array}$ & 53.01 & 9.74 & & 16.02 \\
\hline
\end{tabular}

\section{Discussion}

\subsection{Validation of $P$. euphratica phenology}

Remote sensing monitoring of vegetation phenology is based on vegetation growth characteristics (LAl, $\mathrm{EVI}, \mathrm{NDVI}$, and other features), and the vegetation phenology is simulated using a mathematical model. This method is different from the traditional ground observation phenology method (Zhang et al., 2021b),and the study results cannot be directly compared with the phenology observed on the ground observation phenology (Shen et al., 2020). However, existing studies showed that the vegetation phenology phase determined by remote sensing data was closely related to those obtained from the 
ground phenology monitoring points (Peng et al., 2017; Zhang et al., 2021a). Ground-based observations of phenology can reflect the relative phenology of $P$. euphratica from a macroscopic perspective and can accurately reflect the changing trend of phenology with time. This study was based on one year's worth of data from the ground phenology monitoring points of $P$. euphratica, and established a remote sensing model of $P$. euphratica phenology. To verify the accuracy of the research results and the applicability of the method, based on the GLASS LAI and MODIS NDVI (MOD09Q1 V6) data of 2006, 2010, and 2014, 25 samples were randomly selected to compare and analyze the results of key phenological phase extraction of $P$. euphratica through the process flow chart steps in Fig. 2 . The results revealed that using the GLASS LAI and MODIS NDVI to extract the phenology of $P$. euphratica yielded higher correlations (SOS: $\mathrm{R}^{2}=0.861, \mathrm{P} \otimes 0.001 ; \mathrm{EOS}: \mathrm{R}^{2}=0.824, \mathrm{P} \otimes 0.001$ ). Overall, this method could quickly identify and extract the key phenological period of $P$. euphratica in a large area, and this study results reliable and have scientific reference value for the study of vegetation phenology in arid areas.

\subsection{Which has a stronger influence on phenology in arid areas, runoff, or rainfall?}

Water is a key climatic factor restricting vegetation growth in arid areas (Gao et al., 2018; Ying et al., 2018). The phenological characteristics of $P$. euphratica in the Tarim River Basin are affected by rainfall and runoff. Rainfall directly increases soil moisture and provides direct absorption by the roots of $P$. euphratica (Song et al., 2016; Luo et al., 2019). On the other hand, runoff compensates the groundwater so that the groundwater depth becomes shallow and is absorbed by the roots of $P$. euphratica (Zhou et al., 2010; Zhou et al., 2020). Based on the annual runoff and rainfall data, this study used the grey correlation method to explore the grey correlation grade between $P$. euphratica phenology and annual rainfall and runoff. The results demonstrated that the grey correlation grade between runoff and phenology is higher than that between rainfall and phenology (Fig. 11). Precipitation is scarce in arid areas, and $P$. euphratica growth is not sensitive to precipitation events, which is consistent with previous research results (Xu and Li, 2006; Xu et al., 2011). However, runoff affects the growth of $P$. euphratica by replenishing the groundwater table, which is then absorbed by the roots of $P$. euphratica; hence there is a certain lag effect (Liao et al.,2020). Therefore, the grey correlation grade of rainfall and runoff for the phenology of $P$. euphratica is low, but runoff is still the dominant factor, which is easy to regulate and control. The regulation of runoff and the stable control or reduction of shallow groundwater depth may weaken the impact of global climate change on the phenology of $P$. euphratica.

\subsection{Relationships between phenology of $P$. euphratica and climatic factors}

Phenological research of $P$. euphratica in the Tarim River has been rare. Zhang et al. (2018b) believe that air temperature is the main factor affecting plant phenology in arid and semi-arid areas, and the accumulated temperature should therefore be the condition used to judge $P$. euphratica phenology. She monitored the phenology of $P$. euphratica by taking the date the daily average temperature reached $\geq 5$ 
${ }^{\circ} \mathrm{C}$ as the SOS of $P$. euphratica, and the date of daily average temperature reached $\leq 5{ }^{\circ} \mathrm{C}$ as the EOS in Hexi Corridor (Zhang et al., 2018b). Her results showed that the SOS of $P$. euphratica was delayed, while the EOS was advanced, which was consistent with this study's results. However, our study showed that spring sunshine duration (SD) and average air temperature (AT) controlled the SOS and EOS. Moreover, vegetation phenology is affected by many factors such as geographical factors and climatic factors. Using a single accumulated temperature as the criterion for judging the phenology of $P$. euphratica cannot directly reflect this cycle, and this method is not rigorous.

In this study, the SOS of P. euphratica was delayed by about 5.3 days/10a, and EOS was advanced by about 3.1 days/10a. while other studies have the opposite results (Liang et al., 2016; Karami et al., 2017; Zheng et al., 2018; Wang et al., 2019). However, the SOS was negatively correlated with ST, ET and AT, but positively correlated with SD, PR, and RH, while the relationships between the EOS and meteorological factors were opposite. The discovery is exciting, in which SOS and EOS were dominated by SD, followed by AT. This result suggested that the sunshine duration increase may lead to later SOS and earlier EOS, while the air temperature increase may lead to earlier SOS and later EOS. These results, which the air temperature increase may lead to earlier SOS and later EOS, are consistent with the findings of Tao et al. (2017) and Wang et al. (2019), who reported that the SOS was advanced and EOS was delayed as the temperature increased. Therefore, it is reasonable that the SOS displays a later trend and EOS shows an earlier trend due to the microclimate of this region is different. In addition, vegetation phenology is regional, which is closely related to species, geographical factors, and climatic factors. The response of vegetation phenology to climate change is not universally identical in different regions (Che et al., 2014; Zhang et al., 2021b). Meanwhile, the spring climatic factors had a great influence on the SOS of $P$. euphratica, while the EOS was mainly affected by the autumn climatic factors. As is mentioned above, the response of different vegetation phenology to climate change is not universally identical in different regions. Therefore, it is necessary to explore the variations of $P$. euphratica phenology and its response to climate change in the extremely arid area.

\subsection{Advantages and limitations of the study}

Through field investigation, the concentrated distribution of $P$. euphratica has decreased (Zhao et al., 2016a; Chen et al., 2018). P. euphratica has gradually declined due to climate changes and disturb by human activities, its vegetation coverage is low (Liao et al., 2020; Zhou et al., 2020). the retrieval accuracy of the spatio-temporal patterns of $P$. euphratica phenology using $1 \mathrm{~km} \times 1 \mathrm{~km}$ GLASS LAl remote sensing data is not high. Moreover, considering that there is a wide range of mixed pixels in satellite remote sensing data, the spatial resolution of remote sensing data will affect the accuracy of $P$. euphratica phenological feature inversion. Therefore, To solve the above two problems, this study utilized a grid spatial sampling strategy to select typical sample areas in order to obtain $P$. euphratica phenological information. Then, based on $P$. euphratica spatial distribution data and phenological characteristics data, the Kriging interpolation method was employed to obtain $P$. euphratica phenological characteristics spatial distribution data in the upper Tarim River basin, thereby reducing the impact of the above two problems. Although there are some errors in the spatial pattern of $P$. euphratica phenology obtained by 
the Kriging interpolation method, the study objectives are to explore the changing trend of $P$. euphratica phenology in arid areas and its response to climate change. Thus, it has little influence on the spatial distribution pattern and temporal change trend of $P$. euphratica phenology. This paper has provided an approach that the satellite product data is used to reveal the spatio-temporal variations of the phenology of vegetation, plant community, and a specific tree species, which the spatial aggregation and coverage are low.

However, due to the limitation of vegetation coverage and aggregation degree of $P$. euphratica in arid areas, this study needs a longer time-series and higher spatial resolution remote sensing data to reveal the phenological characteristics of $P$. euphratica. In addition, key periods (spring, SOS preseason, autumn, EOS preseason, annual) that affect the phenology of $P$. euphratica were divided subjectively, which has a certain subjectivity. Thus, answering these questions await further investigation.

\section{Conclusions}

Vegetation phenology is very sensitive to climate change in extremely arid regions, and is thus the best indicator of climate change as well as an essential indicator of ecosystem function. This is of great significance to the vegetation ecosystem in arid regions. Using the GLASS LAI time-series data from 2002-2016, the Spatio-temporal characteristics of $P$. euphratica phenology and their responses to climate change in the upper Tarim River basin were explored. This study revealed that during this period the SOS of $P$. euphratica was delayed, while the EOS advanced, so the growing season was shortened in the study area. The phenology of $P$. euphratica was extensively changed, with high spatial heterogeneity. The spring climatic factors had a great influence on the SOS of $P$. euphratica, while the EOS was mainly affected by the autumn climatic factors. The ranked order correlation between meteorological factors and the phenology of $P$. euphratica ranked was $\mathrm{SD}>\mathrm{AT}>\mathrm{EA}>\mathrm{RH}>\mathrm{ST}>\mathrm{PR}$, implying that it is not easy to characterize phenological change with simple climate data. This difficulty is due to the interaction between the SOS in spring and the EOS in autumn, as well as the comprehensive influence of multiple

climatic factors on vegetation phenology change, which have not been adequately considered in current vegetation phenology research and ecosystem models. This study also revealed that the SOS was negatively correlated with ST and AT, but positively correlated with SD, while the relationships between the EOS and meteorological factors were opposite. Due to the scarcity of rainfall in extremely arid regions, vegetation growth primarily depends on groundwater recharge, so the phenology of $P$. euphratica has a higher correlation with runoff.

\section{Declarations}

\section{Acknowledgments:}

This research was funded by the Agricultural Science and Technology Innovation Program (ASTIP) of Chinese Academy of Agricultural Sciences (CAAS-ASTIP-2016-All), the China's Xinjiang Production and Construction Corps' (XPCC) Key Science and Technology Project (No.2019AB002), and the Strategic 
Priority Research Program of the Chinese Academy of Sciences (No.XDA19030302). We would like to thank the National Earth System Science Data Center, National Science \& Technology Infrastructure of China. (http://www.geodata.cn) for their data support.

\section{Conflict of Interest Statement:}

We declare that we do not have any commercial or associative interest that represents a conflict of interest in connection with the work submitted.

\section{Author Contributions:}

Hualin Li: Formal analysis, Writing - original draft. Jianzhong Feng: Data curation, Software, Visualization. Linyan Bai: Conceptualization, Methodology, Writing - review \& editing. Jianjun Zhang: Data curation, Software.

\section{References}

1. An S, Zhang X, Chen X, Yan D, Henebry G (2018) An Exploration of Terrain Effects on Land Surface Phenology across the Qinghai-Tibet Plateau Using Landsat ETM + and OLI Data. Remote Sens 10:1069

2. Araghi A, Martinez CJ, Adamowski J, Olesen JE (2019) Associations between large-scale climate oscillations and land surface phenology in Iran. Agric For Meteorol 278:107682

3. Bornez K, Descals A, Verger A, Penuelas J (2020) Land surface phenology from VEGETATION and PROBA-V data. Assessment over deciduous forests. Int J Appl Earth Obs Geoinf 84, 11

4. Burgess MD, Smith KW, Evans KL, Leech D, Pearce-Higgins JW, Branston CJ, Briggs K, Clark JR, du Feu CR, Lewthwaite K, Nager RG, Sheldon BC, Smith JA, Whytock RC, Willis SG, Phillimore AB (2018) Tritrophic phenological match-mismatch in space and time. Nat Ecol Evol 2:970

5. Cai Z, Jönsson P, Jin H, Eklundh L (2017) Performance of Smoothing Methods for Reconstructing NDVI Time-Series and Estimating Vegetation Phenology from MODIS Data. Remote Sens 9:1271

6. Che M, Chen B, Innes JL, Wang G, Dou X, Zhou T, Zhang H, Yan J, Xu G, Zhao H (2014) Spatial and temporal variations in the end date of the vegetation growing season throughout the QinghaiTibetan Plateau from 1982 to 2011. Agric. For. Meteorol. 189-190, 81-90

7. Chen X, Wang D, Chen J, Wang C, Shen M (2018) The mixed pixel effect in land surface phenology: A simulation study. Remote Sens Environ 211:338-344

8. Chen Y, Li Z, Fan Y, Wang H, Deng H (2015) Progress and prospects of climate change impacts on hydrology in the arid region of northwest China. Environ Res 139:11-19

9. Delbart N, Beaubien E, Kergoat L, Le Toan T (2015) Comparing land surface phenology with leafing and flowering observations from the PlantWatch citizen network. Remote Sens Environ 160:273-280

10. Eusemann P, Petzold A, Thevs N, Schnittler M (2013) Growth patterns and genetic structure of Populus euphratica Oliv. (Salicaceae) forests in NW China - Implications for conservation and 
management. For Ecol Manage 297:27-36

11. Gao B, Li J, Wang XS (2020) Impact of frozen soil changes on vegetation phenology in the source region of the Yellow River from 2003 to 2015. Theoret Appl Climatol 141:1219-1234

12. Gao X, Wang A, Zhao Y, Zhao X, Sun M, Du J, Gang C (2018) Study on Water Suitability of Apple Plantations in the Loess Plateau under Climate Change. Int. J. Env. Res. Public Health 15

13. Geng X, Zhou X, Yin G, Hao F, Zhang X, Hao Z, Singh VP, Fu YH (2020) Extended growing season reduced river runoff in Luanhe River basin. J Hydrol 582:124538

14. Gonsamo A, Chen JM, Price DT, Kurz WA, Liu J, Boisvenue C, Hember RA, Wu C, Chang K-H (2013) Improved assessment of gross and net primary productivity of Canada's landmass. J Geophys Res Biogeosci 118:1546-1560

15. Gou S, Miller G (2014) A groundwater-soil-plant-atmosphere continuum approach for modelling water stress, uptake, and hydraulic redistribution in phreatophytic vegetation. Ecohydrology 7:10291041

16. Guo J, Yang X, Niu J, Jin Y, Xu B, Shen G, Zhang W, Zhao F, Zhang Y (2019) Remote sensing monitoring of green-up dates in the Xilingol grasslands of northern China and their correlations with meteorological factors. Int J Remote Sens 40:2190-2211

17. He D, Yi G, Zhang T, Miao J, Li J, Bie X (2018) Temporal and Spatial Characteristics of EVI and Its Response to Climatic Factors in Recent 16 years Based on Grey Relational Analysis in Inner Mongolia Autonomous Region, China. Remote Sens 10:961

18. He L, Jin N, Yu Q (2020) Impacts of climate change and crop management practices on soybean phenology changes in China. Sci Total Environ 707:135638

19. Hotelling H (1935) Relations Between Two Sets of Variates Biometrika 28:321-377

20. Hu L, Fan W, Ren H, Liu S, Cui Y, Zhao P (2018) Spatiotemporal Dynamics in Vegetation GPP over the Great Khingan Mountains Using GLASS Products from 1982 to 2015. Remote Sens 10:488

21. Hu Y, Li H, Wu D, Chen W, Zhao X, Hou M, Li A, Zhu Y (2021) LAl-indicated vegetation dynamic in ecologically fragile region: A case study in the Three-North Shelter Forest program region of China. Ecol. Indicators 120

22. Huang S, Zheng X, Ma L, Wang H, Huang Q, Leng G, Meng E, Guo Y (2020) Quantitative contribution of climate change and human activities to vegetation cover variations based on GA-SVM model. $J$ Hydrol 584:124687

23. Ivanova Y, Kovalev A, Yakubailik O, Soukhovolsky V (2019) The Use of Satellite Information (MODIS/Aqua) for Phenological and Classification Analysis of Plant Communities. Forests 10:561

24. Jin J, Wang Y, Zhang Z, Magliulo V, Jiang H, Cheng M (2017) Phenology Plays an Important Role in the Regulation of Terrestrial Ecosystem Water-Use Efficiency in the Northern Hemisphere. Remote Sens 9:664

25. Jönsson P, Eklundh L (2002) Seasonality extraction by function fitting to time-series of satellite sensor data. IEEE transactions on Geoscience Computers Remote Sensing 40:1824-1832 
26. Karami M, Hansen BU, Westergaard-Nielsen A, Abermann J, Lund M, Schmidt NM, Elberling B (2017) Vegetation phenology gradients along the west and east coasts of Greenland from 2001 to 2015. Ambio 46, S94-S105

27. Keram A, Halik Ü, Keyimu M, Aishan T, Mamat Z, Rouzi A (2019) Gap dynamics of natural Populus euphratica floodplain forests affected by hydrological alteration along the Tarim River: Implications for restoration of the riparian forests. For Ecol Manage 438:103-113

28. Lang P, Ahlborn J, Schäfer P, Wommelsdorf T, Jeschke M, Zhang X, Thomas FM (2016) Growth and water use of Populus euphratica trees and stands with different water supply along the Tarim River, NW China. For Ecol Manage 380:139-148

29. Li H, Bai L, Feng J, Gao H, Ran Q, Yu T, Gao W (2019a) Analysis of spatio-temporal characteristics of Populus euphratica forests in the Yarkand River Basin, Xinjiang. Acta Ecol Sin 39:5080-5094 (in Chinese)

30. Li J, Xiao Z (2020) Evaluation of the version 5.0 global land surface satellite (GLASS) leaf area index product derived from MODIS data. Int J Remote Sens 41:9140-9160

31. Li P, He Z, He D, Xue D, Wang Y, Cao S (2019b) Fractional vegetation coverage response to climatic factors based on grey relational analysis during the 2000-2017 growing season in Sichuan Province, China. Int J Remote Sens 41:1170-1190

32. Li X, Zhang L, Luo T (2020) Rainy season onset mainly drives the spatiotemporal variability of spring vegetation green-up across alpine dry ecosystems on the Tibetan Plateau. Scientific Reports 10

33. Liang S, Shi P, Li H (2016) Urban spring phenology in the middle temperate zone of China: dynamics and influence factors. Int J Biometeorol 60:531-544

34. Liao SM, Xue LQ, Dong ZC, Zhu BL, Zhang K, Wei Q, Fu FB, Wei GH (2020) Cumulative ecohydrological response to hydrological processes in arid basins. Ecol. Indicators 111

35. Lim CH, Jung SH, Kim AR, Kim NS, Lee CS (2020) Monitoring for Changes in Spring Phenology at Both Temporal and Spatial Scales Based on MODIS LST Data in South Korea. Remote Sens 12:3282

36. Luo YY, Zuo XA, Li YL, Zhang TH, Zhang R, Chen JL, Lv P, Zhao XY (2019) Community carbon and water exchange responses to warming and precipitation enhancement in sandy grassland along a restoration gradient. Ecol Evol 9:10938-10949

37. Ma J, Xiao X, Li R, Zhao B, Myint SW (2020) Enhanced spring phenological temperature sensitivity explains the extension of carbon uptake period in temperate forest protected areas. For Ecol Manage 455:117679

38. Meier GA, Brown JF, Evelsizer RJ, Vogelmann JE (2015) Phenology and climate relationships in aspen (Populus tremuloides Michx.) forest and woodland communities of southwestern Colorado. Ecol Indicators 48:189-197

39. Meng F, Niu H, Suonan J, Zhang Z, Wang Q, Li B, Lv W, Wang S, Duan J, Liu P (2019) Divergent responses of community reproductive and vegetative phenology to warming and cooling: asymmetry vs symmetry. Front Plant Sci 10:1310 
40. Misra G, Asam S, Menzel A (2021) Ground and satellite phenology in alpine forests are becoming more heterogeneous across higher elevations with warming. Agric For Meteorol 303:108383

41. Nilsson ALK, Slagsvold T, Rostad OW, Knudsen E, Jerstad K, Cadahia L, Reitan T, Helberg M, Walseng B, Stenseth NC (2019) Territory location and quality, together with climate, affect the timing of breeding in the white-throated dipper. Sci Rep 9:7671

42. Noy-Meir I (1973) Desert ecosystems: environment and producers. Annu Rev Ecol Syst 4:25-51

43. Pabon-Moreno DE, Musavi T, Migliavacca M, Reichstein M, Mahecha MDJB (2020) Ecosystem physio-phenology revealed using circular statistics. Biogeoences 17:3991-4006

44. Peng D, Zhang X, Wu C, Huang W, Gonsamo A, Huete AR, Didan K, Tan B, Liu X, Zhang B (2017) Intercomparison and evaluation of spring phenology products using National Phenology Network and AmeriFlux observations in the contiguous United States. Agric For Meteorol 242:33-46

45. Schimel DS (2010) Drylands in the Earth System. Science 327:418-419

46. Schwieder M, Leitao PJ, Bustamante MMD, Ferreira LG, Rabe A, Hostert P (2016) Mapping Brazilian savanna vegetation gradients with Landsat time series. Int J Appl Earth Obs Geoinf 52:361-370

47. Shen M, Jiang N, Peng D, Rao Y, Huang Y, Fu YH, Yang W, Zhu X, Cao R, Chen X, Chen J, Miao C, Wu C, Wang T, Liang E, Tang $Y$ (2020) Can changes in autumn phenology facilitate earlier green-up date of northern vegetation? Agric. For Meteorol 291:108077

48. Song XL, Wang YH, Lv XM (2016) Responses of plant biomass, photosynthesis and lipid peroxidation to warming and precipitation change in two dominant species (Stipa grandis and Leymus chinensis) from North China Grasslands. Ecol Evol 6:1871-1882

49. Steven P, Norman, WWH.a.WMC (2017) Spring and Autumn Phenological Variability across Environmental Gradients of Great Smoky Mountains National Park, USA. Remote Sens 9:407

50. Suepa T, Qi J, Lawawirojwong S, Messina JP (2016) Understanding spatio-temporal variation of vegetation phenology and rainfall seasonality in the monsoon Southeast Asia. Environ Res 147:621-629

51. Tao ZX, Wang HJ, Liu YC, Xu YJ, Dai JH (2017) Phenological response of different vegetation types to temperature and precipitation variations in northern China during 1982-2012. Int J Remote Sens 38:3236-3252

52. Tong XY, Tian F, Brandt M, Liu Y, Zhang WM, Fensholt R (2019) Trends of land surface phenology derived from passive microwave and optical remote sensing systems and associated drivers across the dry tropics 1992-2012. Remote Sens Environ 232:12

53. Wang C, Li J, Liu QH, Zhong B, Wu SL, Xia CF (2017) Analysis of Differences in Phenology Extracted from the Enhanced Vegetation Index and the Leaf Area Index. Sensors 17

54. Wang Y, Luo Y, Shafeeque M (2019) Interpretation of vegetation phenology changes using daytime and night-time temperatures across the Yellow River Basin, China. Sci. Total Environ. 693

55. Wu C, Hou X, Peng D, Gonsamo A, Xu S (2016) Land surface phenology of China's temperate ecosystems over 1999-2013: Spatial-temporal patterns, interaction effects, covariation with climate 
and implications for productivity. Agric For Meteorol 216:177-187

56. Wu K, Xu W, Yang W (2020) Effects of precipitation changes on soil bacterial community composition and diversity in the Junggar desert of Xinjiang. China PeerJ 8:e8433

57. Xiang Y, Xiao Z, Ling S, Wang J, Song J (2014) Validation of Global LAnd Surface Satellite (GLASS) leaf area index product. Journal of $\mathrm{i}^{2} / 4^{2}$ emote Sensing 18:573-584

58. Xu G-Q, Li Y, Xu H (2011) Seasonal variation in plant hydraulic traits of two co-occurring desert shrubs, Tamarix ramosissima and Haloxylon ammodendron, with different rooting patterns. Ecol Res 26:1071-1080

59. Xu H, Li Y (2006) Water-use strategy of three central Asian desert shrubs and their responses to rain pulse events. Plant Soil 285:5-17

60. Xu J, Li W, Ji M, Lu F, Dong S (2010) A comprehensive approach to characterization of the nonlinearity of runoff in the headwaters of the Tarim River, western China. Hydrol Processes 24:136146

61. Xu XJ, Zhou GM, Du HQ, Mao FJ, Xu L, Li XJ, Liu LJ (2020) Combined MODIS land surface temperature and greenness data for modeling vegetation phenology, physiology, and gross primary production in terrestrial ecosystems. Sci Total Environ 726:11

62. Xu Z, Liu Q, Du W, Zhou G, Qin L, Sun Z (2021) Modelling leaf phenology of some trees with accumulated temperature in a temperate forest in northeast China. For Ecol Manage 489:119085

63. Ying W, Chunxia W, Jukui Z, Chunqing WJR.S.o.s., 2018. The reproductive strategy in a Chloris virgata population in response to precipitation regimes. R Soc Open Sci 5, 180607

64. Yu T, Feng Q, Si J, Xi H, Su Y, Mitchell PJ, Pinkard EA (2021) Flooding constrains tree water use of a riparian forest in the lower Heihe River Basin, Northwest China. Sci Total Environ 760:144069

65. Yuan G, Zhang P, Shao M-a, Luo Y, Zhu X (2014) Energy and water exchanges over a riparian Tamarix spp. stand in the lower Tarim River basin under a hyper-arid climate. Agric For Meteorol 194:144-154

66. Yuan MX, Zhao L, Lin AW, Wang LC, Li QJ, She DX, Qu S (2020) Impacts of preseason drought on vegetation spring phenology across the Northeast China Transect. Sci Total Environ 738:10

67. Zhang J, Tong X, Zhang J, Meng P, Li J, Liu P (2021a) Dynamics of phenology and its response to climatic variables in a warm-temperate mixed plantation. For Ecol Manage 483:118785

68. Zhang J, Tong X, Zhang J, Meng P, Li J, Liu P (2021b) Dynamics of phenology and its response to climatic variables in a warm-temperate mixed plantation. For Ecol Manage 483:118785

69. Zhang Q, Kong D, Shi P, Singh VP, Sun P (2018a) Vegetation phenology on the Qinghai-Tibetan Plateau and its response to climate change (1982-2013). Agric For Meteorol 248:408-417

70. Zhang W, Liu P, Feng Q, Wang T, Wang T (2018b) The spatiotemporal responses of Populus euphratica to global warming in Chinese oases between 1960 and 2015. J Geogr Sci 28:579-594

71. Zhao J, Wang Y, Zhang Z, Zhang H, Guo X, Yu S, Du W, Huang F (2016a) The Variations of Land Surface Phenology in Northeast China and Its Responses to Climate Change from 1982 to 2013. Remote Sens 8:400 
72. Zhao Y, Bai L, Feng J, Lin X, Wang L, Xu L, Ran Q, Wang K (2016b) Spatial and Temporal Distribution of Multiple Cropping Indices in the North China Plain Using a Long Remote Sensing Data Time Series. Sensors 16:21

73. Zheng C, Tang X, Gu Q, Wang T, Wei J, Song L, Ma M (2018) Climatic anomaly and its impact on vegetation phenology, carbon sequestration and water-use efficiency at a humid temperate forest. $J$ Hydrol 565:150-159

74. Zhou HH, Chen YN, Li WH, Chen YP (2010) Photosynthesis of Populus euphratica in relation to groundwater depths and high temperature in arid environment, northwest China. Photosynthetica 48:257-268

75. Zhou HH, Chen YN, Zhu CG, Li Z, Fang GH, Li YP, Fu AH (2020) Climate change may accelerate the decline of desert riparian forest in the lower Tarim River, Northwestern China: Evidence from treerings of Populus euphratica. Ecol. Indicators 111

76. Zou F, Li H, Hu Q (2020) Responses of vegetation greening and land surface temperature variations to global warming on the Qinghai-Tibetan Plateau, 2001-2016. Ecol Indicators 119:106867

\section{Figures}
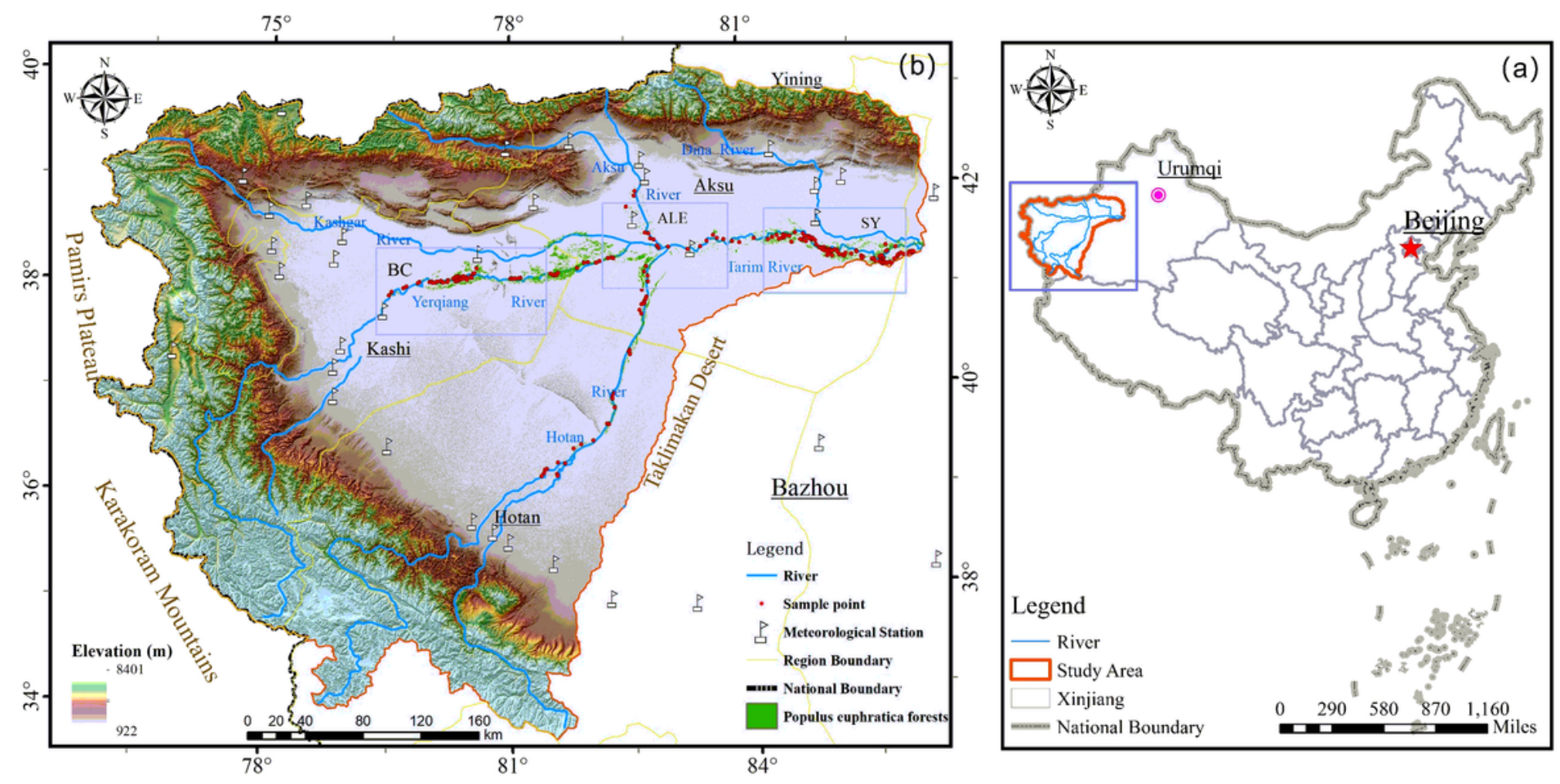

\section{Figure 1}

(a) Study area; (b) Sample points, meteorological stations, and typical sample area of Bachu (BC), Alaer (ALE), and Saya (SY). Note: The designations employed and the presentation of the material on this map do not imply the expression of any opinion whatsoever on the part of Research Square concerning the 
legal status of any country, territory, city or area or of its authorities, or concerning the delimitation of its frontiers or boundaries. This map has been provided by the authors.

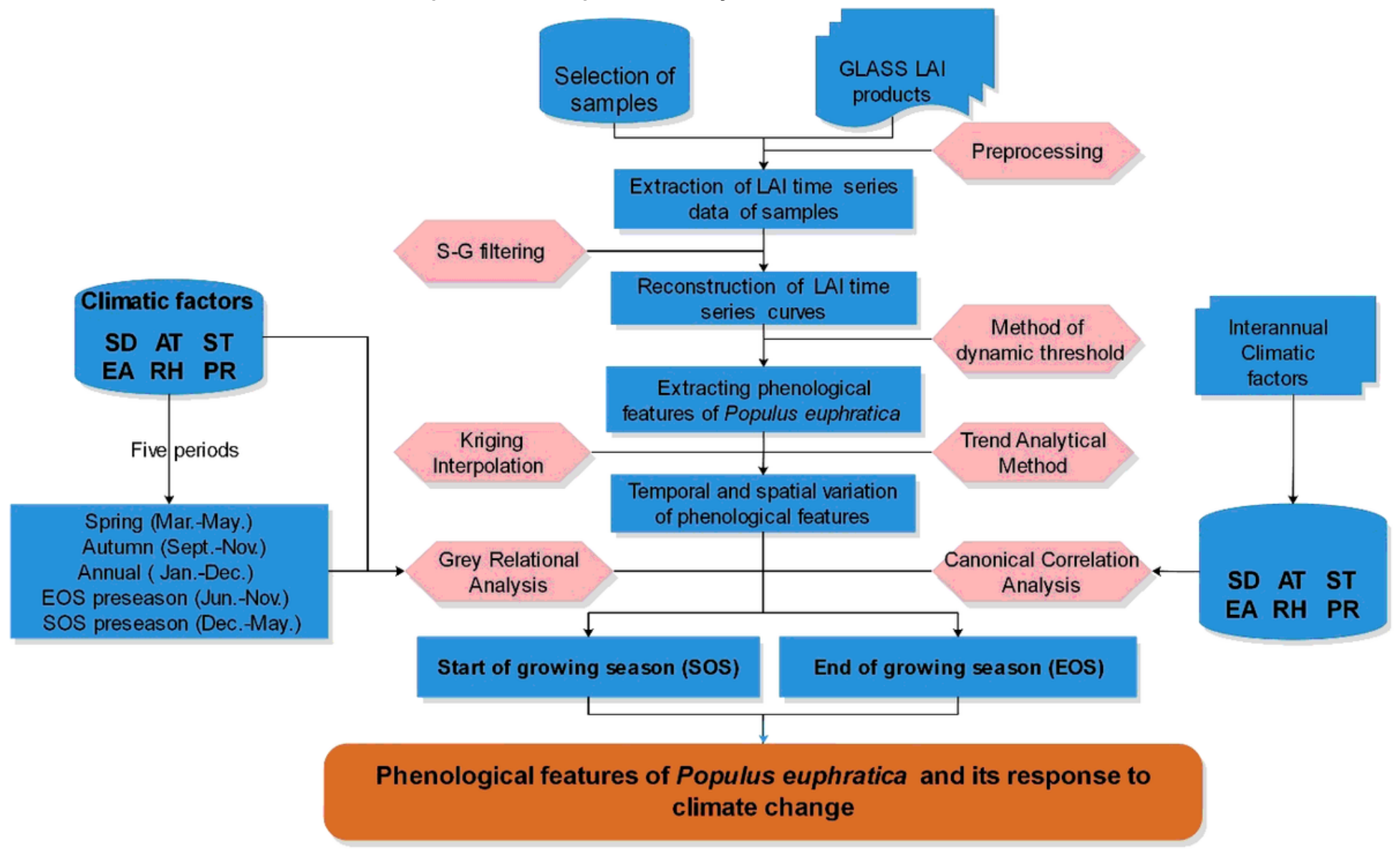

\section{Figure 2}

Schematic diagram of the extraction processes of henological features of P. euphratica. LAl, leaf area index; GLASS, Global LAnd Surface Satellite; SD, sunshine duration; AT, average air temperature; ST, average land surface temperature; EA, effective accumulated temperature; $\mathrm{RH}$, average relative humidity; PR, precipitation; SOS, start of the growing season; EOS, end of growing season, Savitzky-Golay (S-G) filtering.

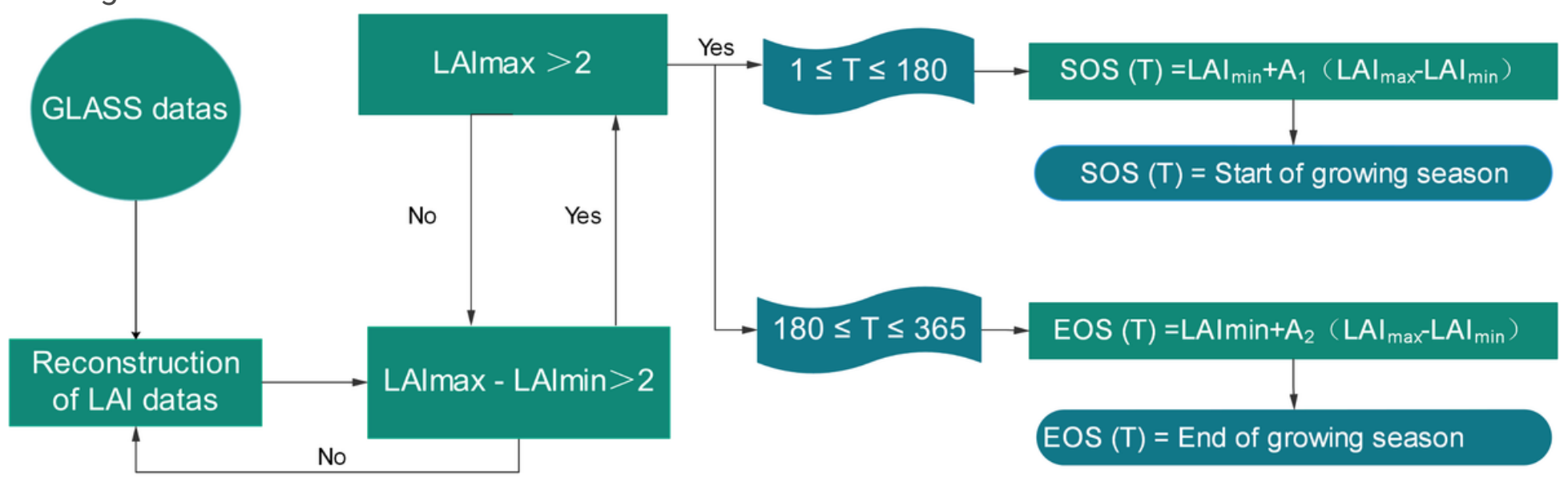

Figure 3 
Flow chart of the dynamic threshold method used to extract the phenological features of $\mathrm{P}$. euphratica $(\mathrm{A} 1=0.2, \mathrm{~A} 2=0.3)$.
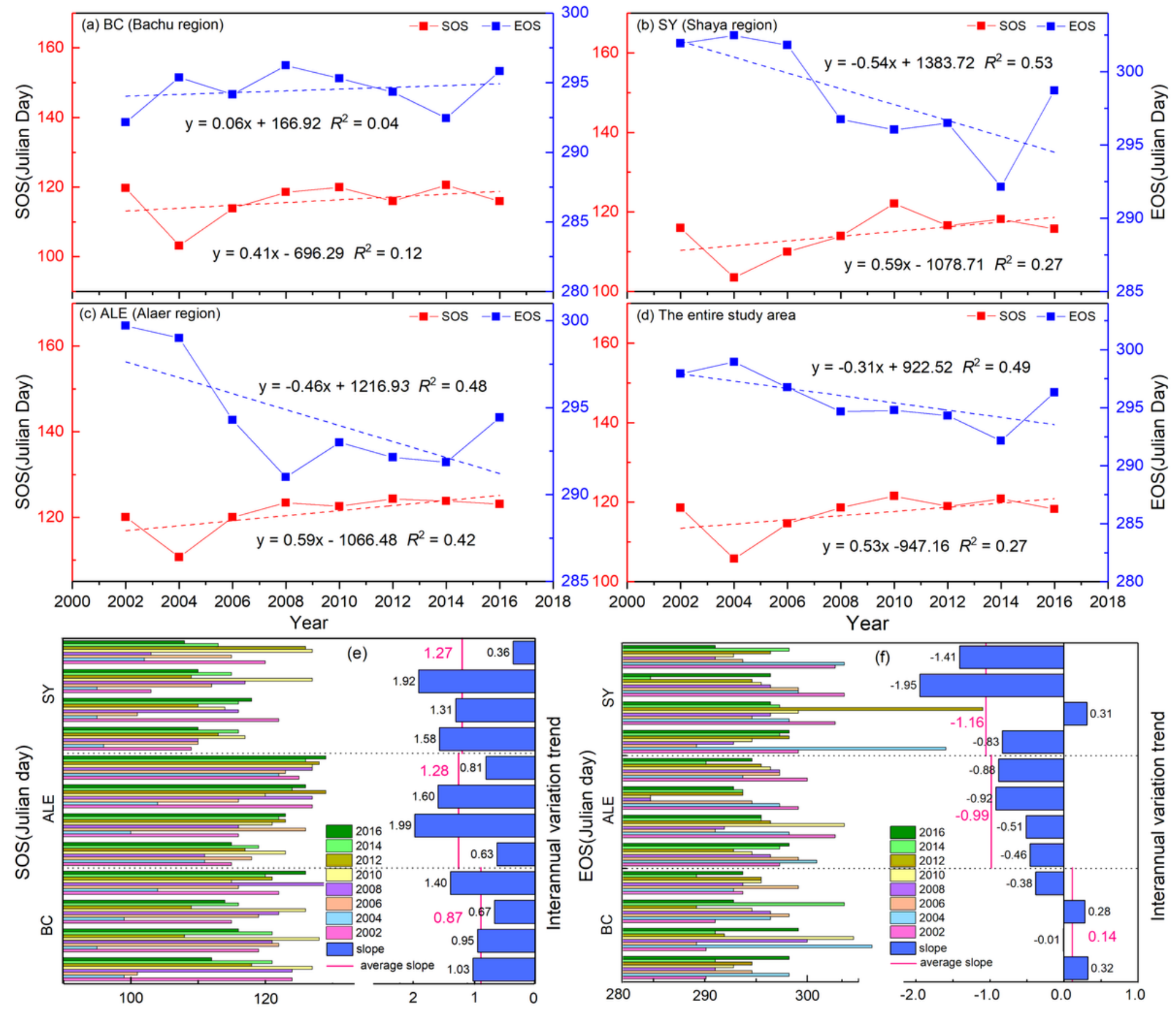

Figure 4

Interannual changes and trends of P. euphratica phenology (SOS, EOS) in the upper Tarim River basin from 2002-2016: (a) Bachu region (BC); (b) Shaya region (SY); (c) Alaer region (ALE); (d) Entire study area; (e) Interannual variation and slope of SOS, and the Julian day of SOS at four random sampling sites in BC, SY, and ALE; (f) Interannual variation and slope of EOS, and the Julian day of EOS at four random sampling sites in $B C, S Y$, and ALE. 


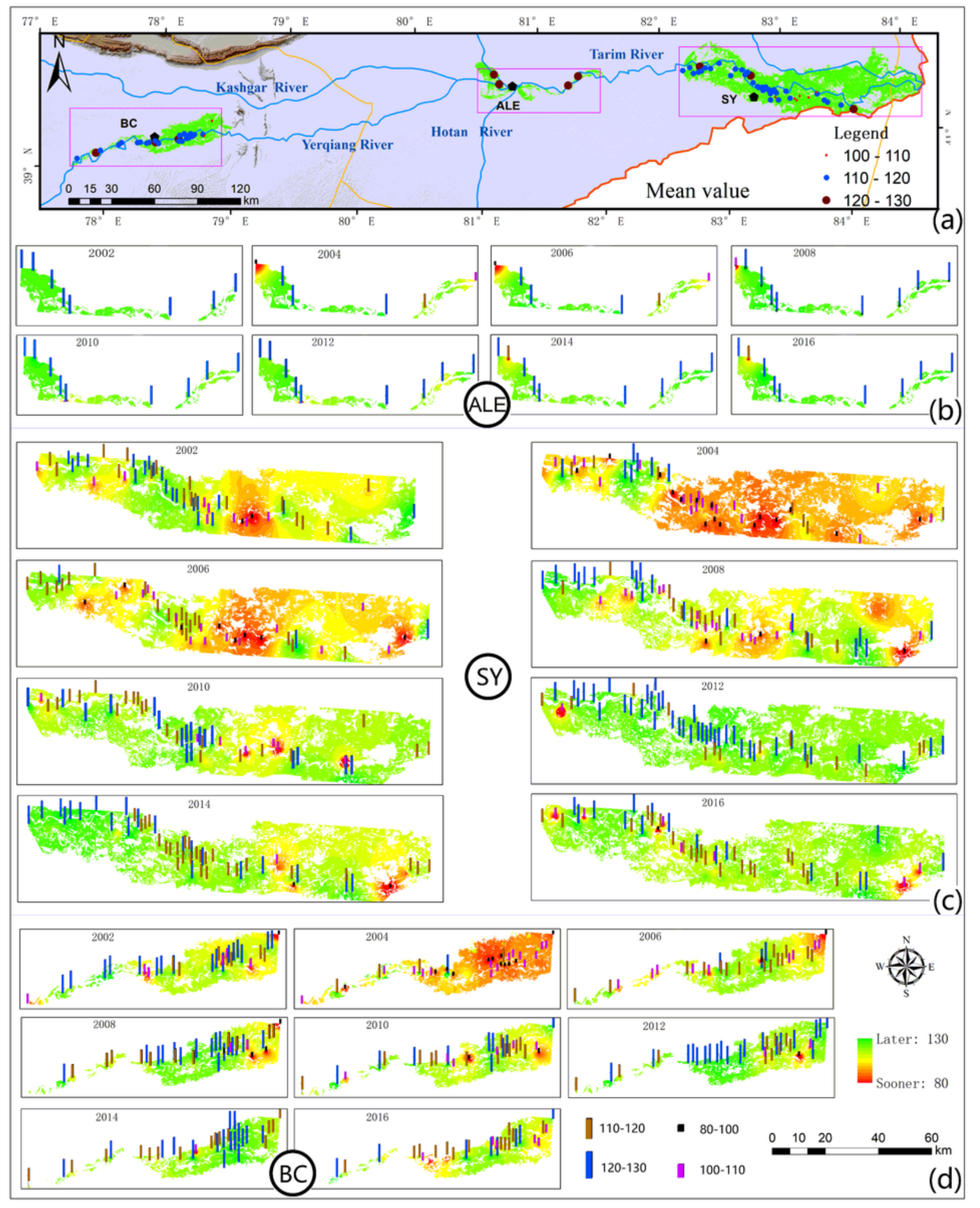

Figure 5

SOS spatial distribution of P. euphratica in the upper Tarim River basin from 2002-2016: (a) Multi-year average; (b) Alaer region; (c) Shaya region; (d) Bachu region. Note: The designations employed and the presentation of the material on this map do not imply the expression of any opinion whatsoever on the part of Research Square concerning the legal status of any country, territory, city or area or of its 
authorities, or concerning the delimitation of its frontiers or boundaries. This map has been provided by the authors.

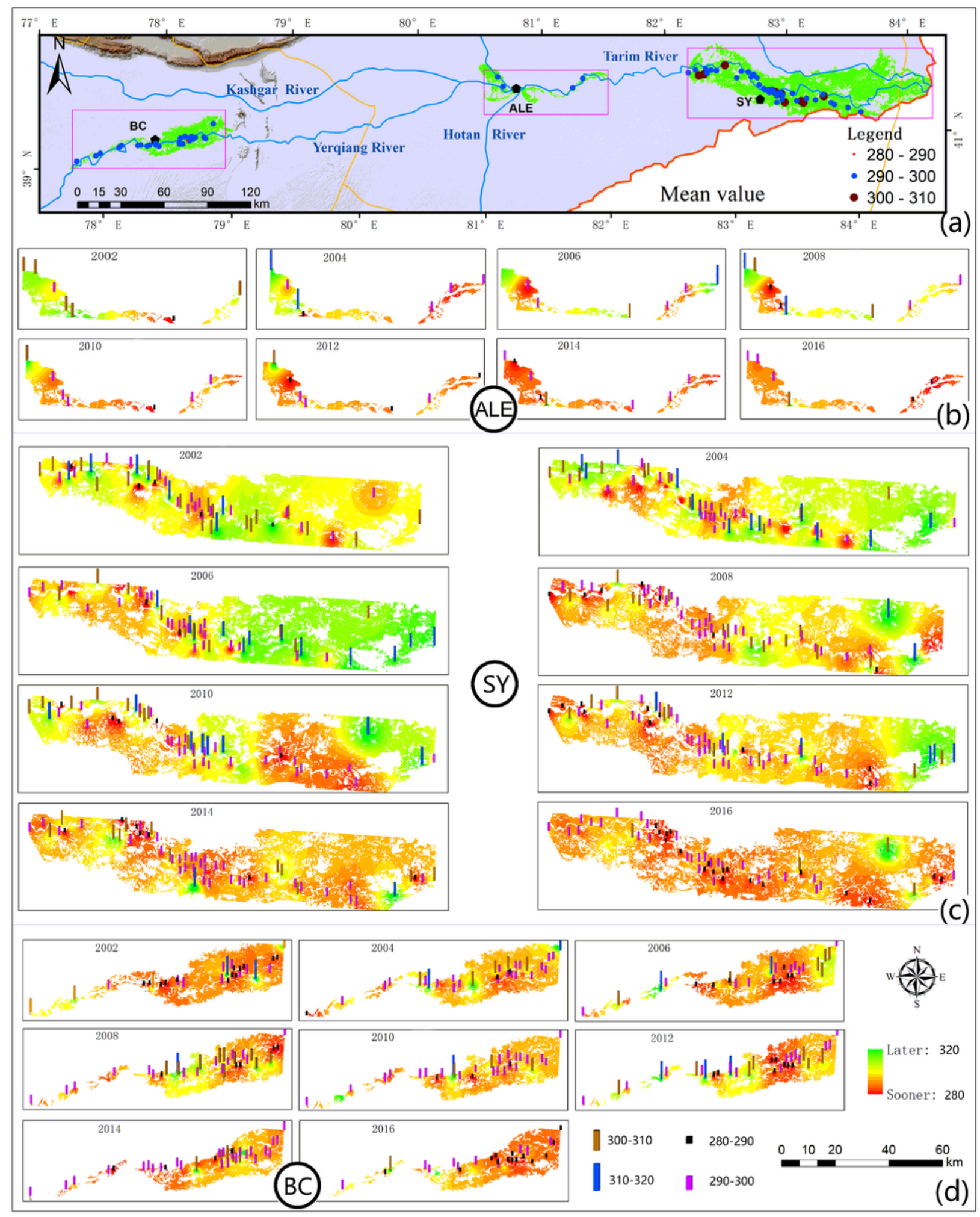

Figure 6

EOS spatial distribution of P. euphratica in the upper Tarim River basin from 2002-2016: (a) Multi-year average; (b) Alaer region; (c) Shaya region; (d) Bachu region. Note: The designations employed and the presentation of the material on this map do not imply the expression of any opinion whatsoever on the 
part of Research Square concerning the legal status of any country, territory, city or area or of its authorities, or concerning the delimitation of its frontiers or boundaries. This map has been provided by the authors.
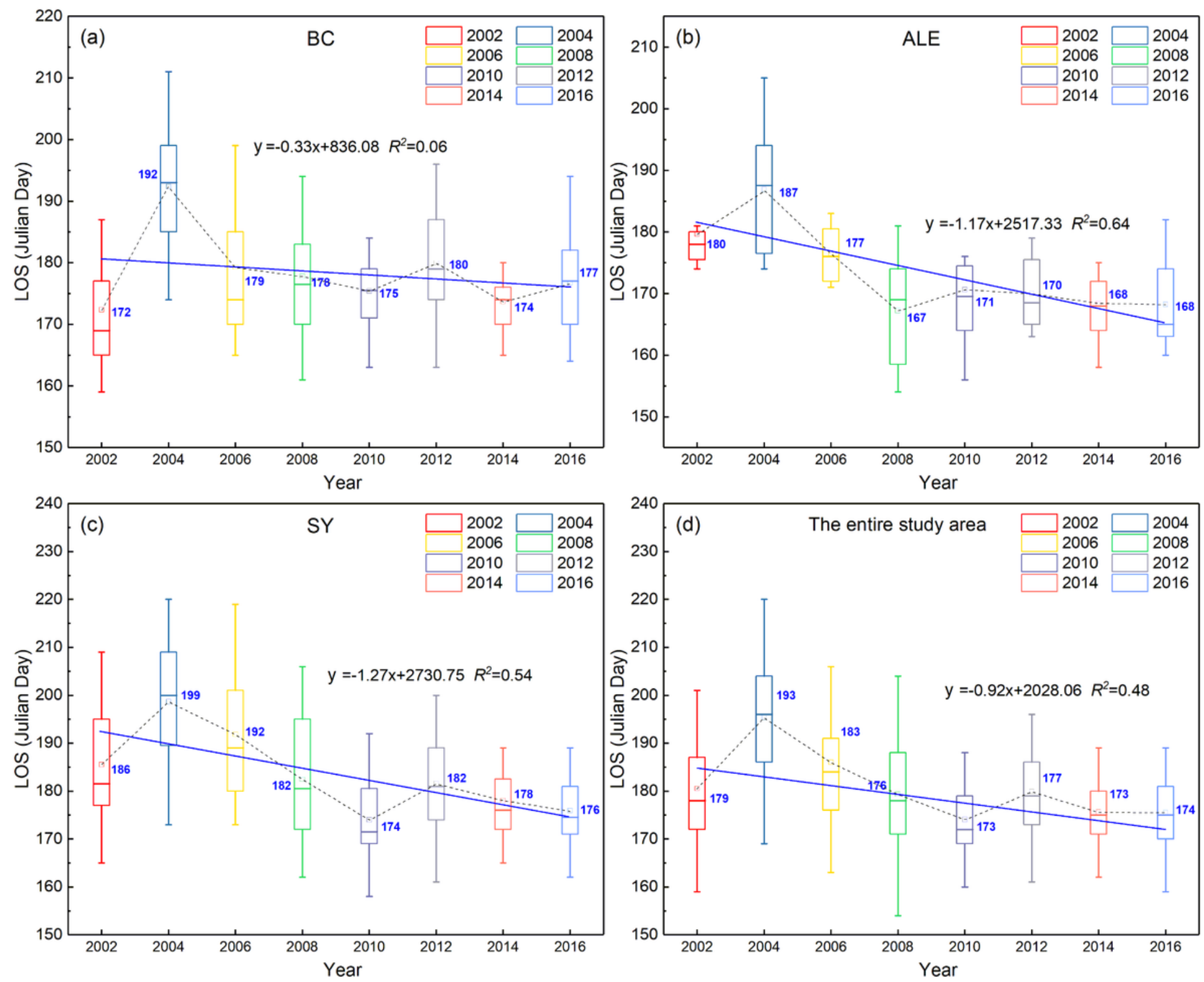

Figure 7

Interannual variation trend of the P. euphratica LOS in the upper Tarim River basin from 2002-2016: (a) Bachu region; (b) Alaer region; (c) Shaya region; (d) Entire study area. 

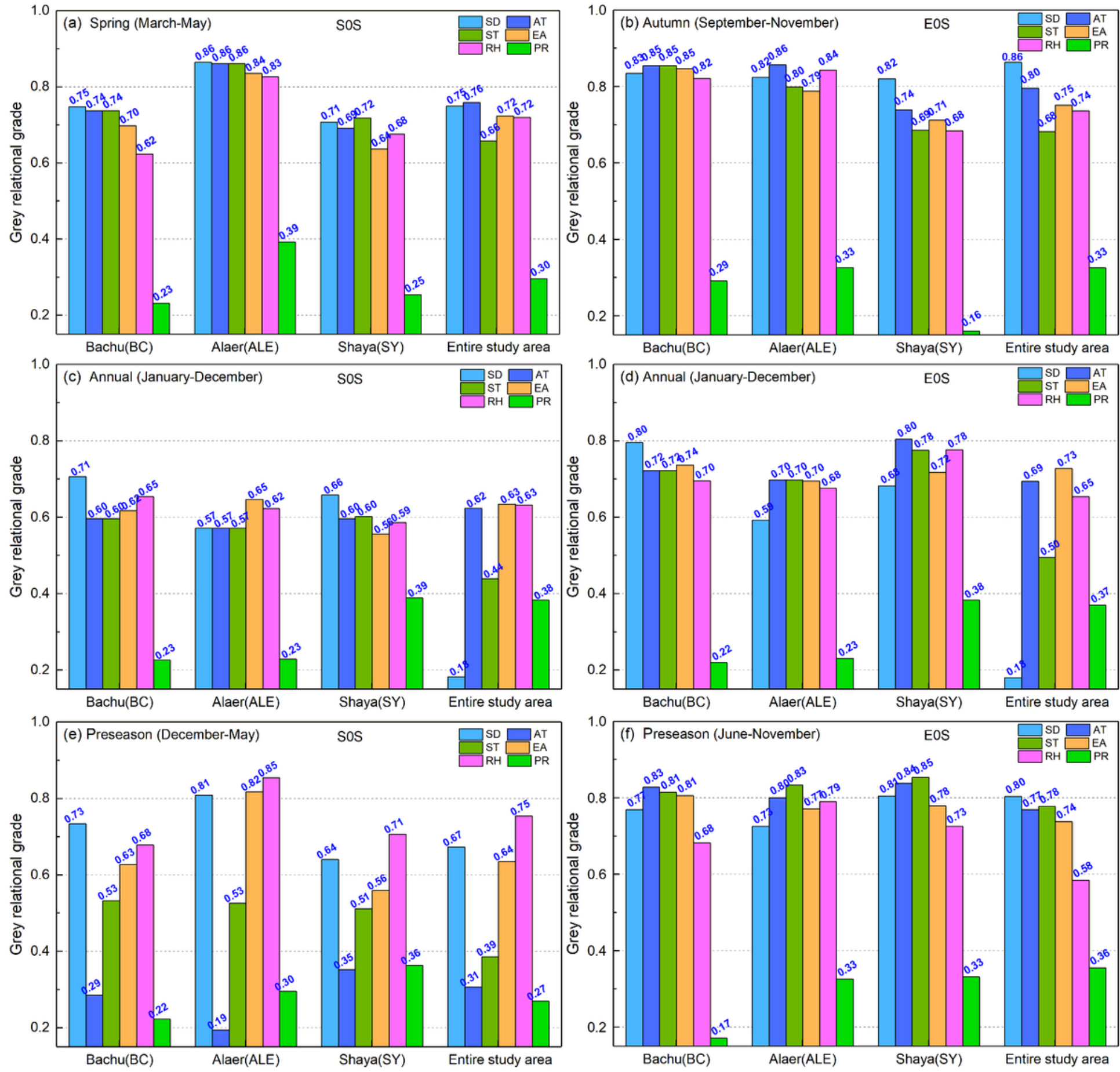

Figure 8

GRA between phenology (SOS and EOS) and climatic factors (SD, AT, ST, EA, RH, PR): (a) GRA between the SOS and climatic factors in spring (March-May); (b) GRA between the EOS and climatic factors in autumn (September-November); (c) GRA between the SOS and the annual (January-December) climatic factors; (d) GRAs between the EOS and the annual (January-December) climatic factors; (e) GRA between the SOS and the SOS preseason (December-May) climatic factors; (f) GRA between the EOS and the EOS preseason (December-May) climatic factors. 


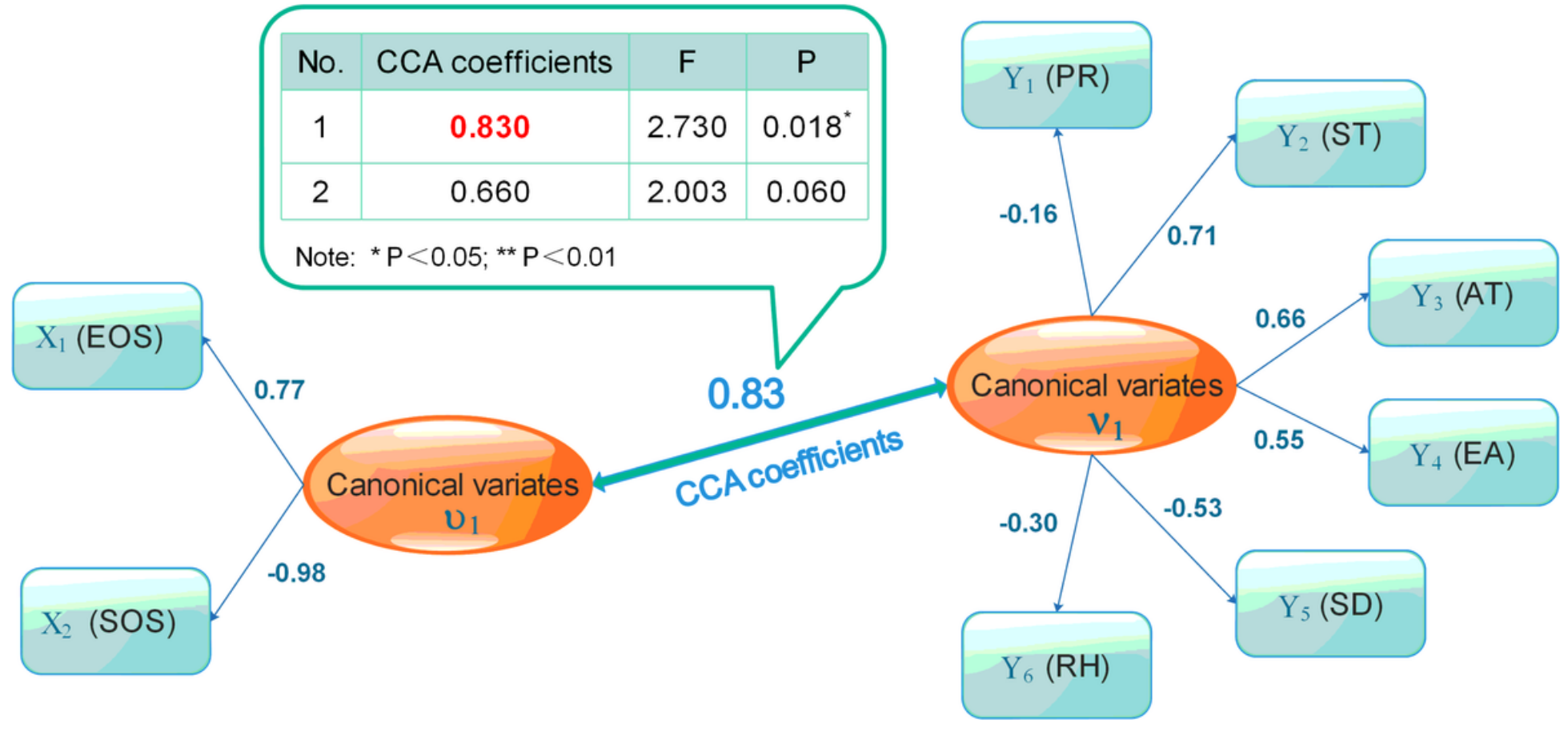

Figure 9

CCA patterns between phenology (SOS and EOS) and climatic factors (SD, AT, ST, EA, RH, PR).
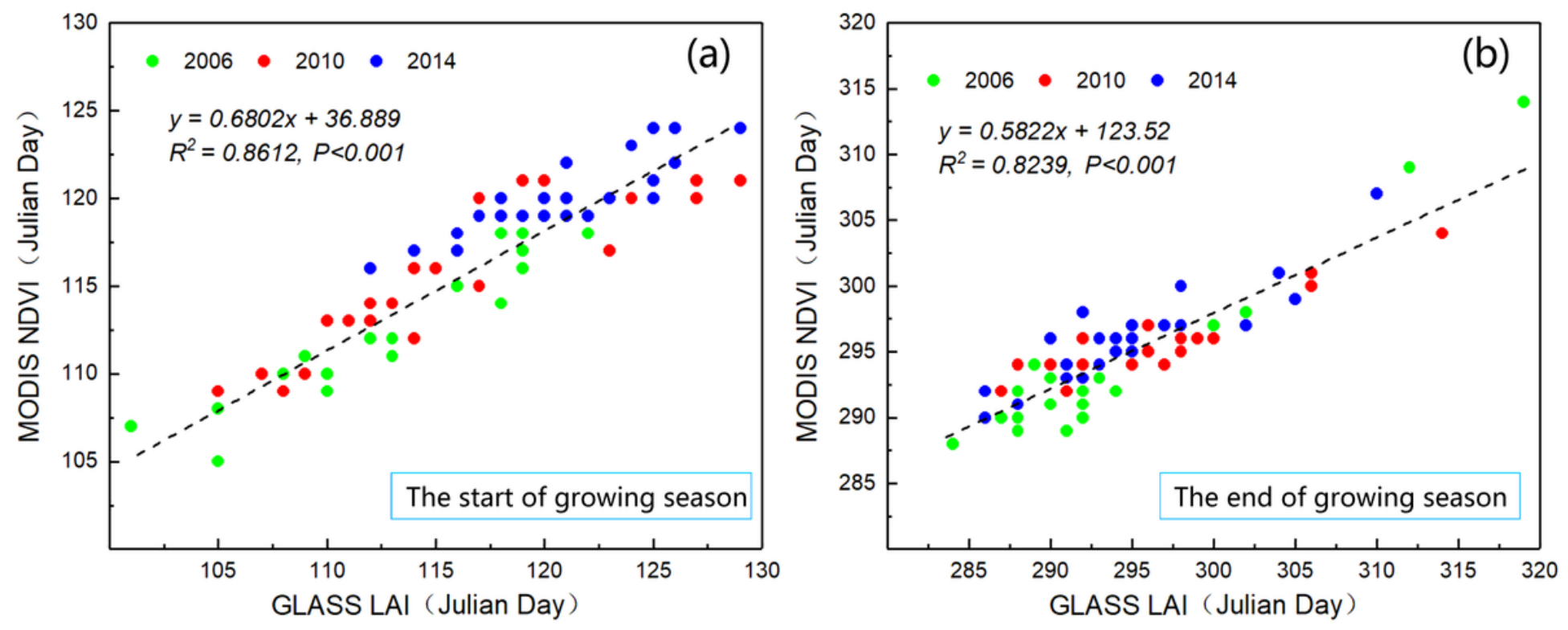

Figure 10

Extraction of P. euphratica phenology based on MODIS NDVI and GLASS LAI data: (a) Start of the growing season (SOS); (b) End of the growing season (EOS). 


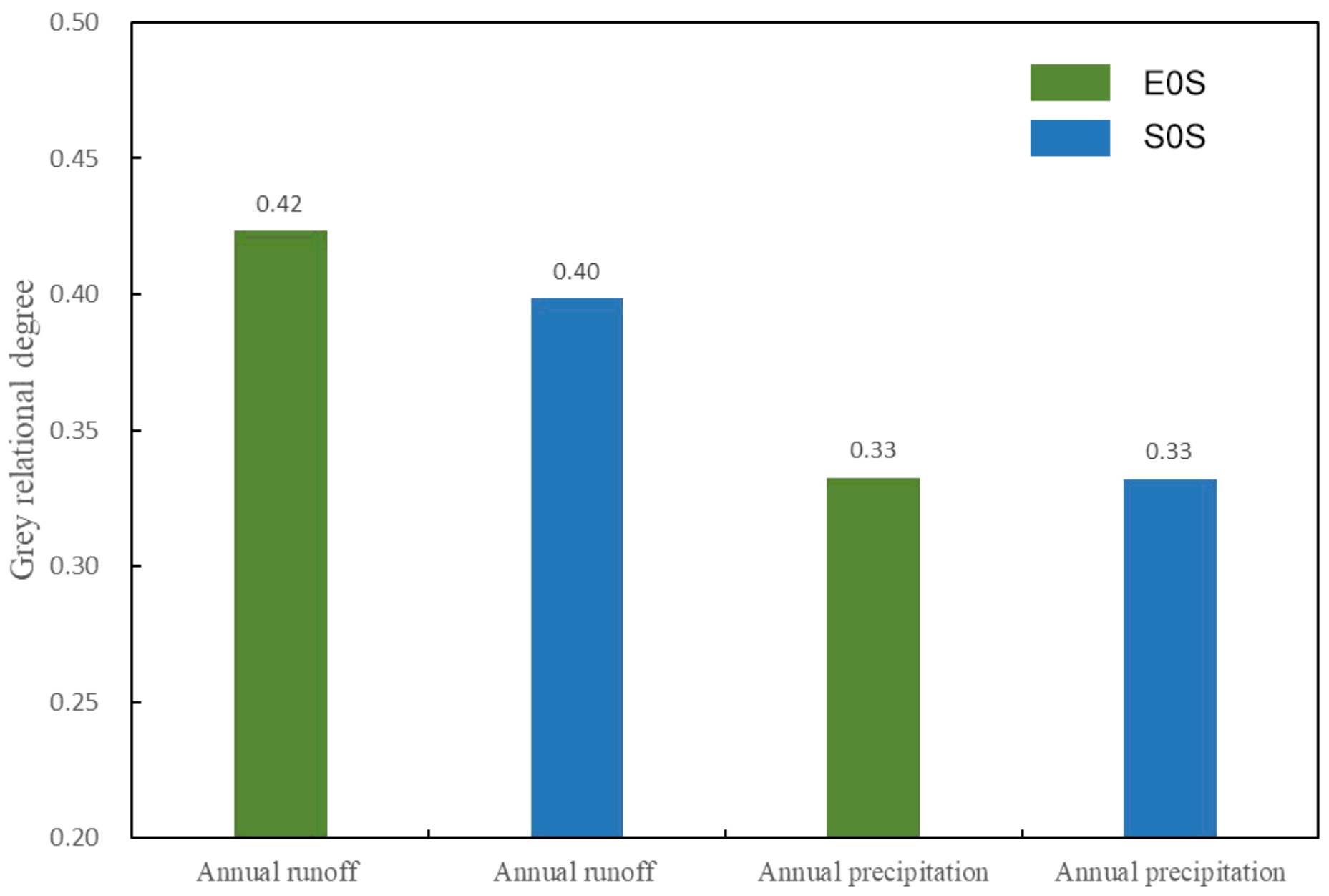

Figure 11

GRA between phenology (SOS and EOS) and water (annual runoff and annual rainfall). 